\title{
Autonomy support in the aquatic motivational healthy program through the SDT
}

\author{
Ricardo Zazo ${ }^{1}$, Fernando Peruyero ${ }^{1}$, Juan Antonio Moreno-Murcia ${ }^{1 *}$
}

ORIGINAL ARTICLE

\begin{abstract}
This study aimed to test an aquatic motivation healthy program based on the self determination theory (SDT), using a quasi-experimental study. The research data come from different physical, psycho-social and behavioral measures made on 49 women. The sample was divided into two groups, an experimental group consisting of 28 women $(\mathrm{M}=43.64 ; \mathrm{SD}=12.06)$, with an average experience of 3.05 years, and a control group composed of 21 women $(M=47.14$; $S D=10.01)$, with an average experience of 2.29 years doing physical exercise in an aquatic environment in a large Spanish city. After the intervention with a program based on the SDT and instructor's autonomy support, both groups perceived physical benefits for health, but the experimental group perceived a better instructor's autonomy support, a better relationship with others and a greater psychological well-being among the practitioners. The information offered in this study may be of interest to promote for instructor part, these type the aquatic physical exercise programs in favor of the population's health.

Keywords: SDT, psychological mediators, psychological well-being, exercise rate, aquatic exercise, health, women.
\end{abstract}

\section{INTRODUCTION}

The latest research on the self determination theory (SDT) confirms that physical activity and sports teachers and instructors can learn how and when to give greater autonomy support to learners or athletes to obtain benefits for health (Chatzisarantis \& Hagger, 2009; Cheon, Reeve, \& Moon, 2012; Edmund, Ntoumanis, \& Duda, 2008; Lonsdale et al., 2013; Rocchi, Pelletier \& Desmarais, 2017; Tessier, Sarrazin, \& Ntoumanis, 2010), despite the different situations that can arise when doing physical exercise and within the sport context (Cheon, Reeve, \& Lee, 2015).

Studies by Duda et al. (2013), Balaguer et al., (2008) and Sarrazin et al., (2002) indicate that the social factor of perceived autonomy support generated by a figure of authority presents a good predictive power, which can lead learners to develop more self-determined motivation. In this sense, the self-determination theory (Deci \& Ryan, 1985, 1991, 2000) stipulates that for beginners to experience higher intrinsic motivation, they should feel that the three psychological basic needs (competence, autonomy and relatedness) are satisfied.

The need for competence reflects the need to perceive that our behavior is effective and we are capable of achieving this. The need for autonomy represents the obligation to perceive that we can control our own actions. Finally, the need for relatedness represents the need to feel a sense of belonging or connection with others. The SDT indicates that individuals seek activities and experiences to accomplish these three fundamental needs, and people should be involved in activities that will provide them with the support to be more self-determined (Deci \& Ryan, 2002).

In a training context, Mageau and Vallerand (2003) have specified some of the key behaviors that contribute to an interpersonal style of autonomy support. They specifically argue that instructor autonomy support is: (a) offering athletes alternatives within the limits and rules, (b) providing athletes with a rationale for doing an activity, (c) seeking and recognizing athletes' feelings, (d) providing athletes with

\footnotetext{
Manuscript received at January $15^{\text {th }}, 2018$; Accepted at September $27^{\text {th }}, 2018$

${ }^{1}$ Universidad Miguel Hernández, Elche, Spain

*E-mail: j.moreno@umh.es
} 
opportunities to take the initiative and act independently, (e) providing feedback on performance, $(f)$ induced control of criticism and comments, as well as limiting the use of rewards, and (g) minimizing behaviors that favor ego participation. This style gives a sense of support for their needs of competence, autonomy and relatedness, and therefore, they believe their coach has a greater interpersonal style of autonomy support. Markland and Tobin (2010), indicated that exercise practitioners should help referral schemes clients to assimilate into the social environment of exercise facilities as well as ensuring that they receive more direct interpersonal support. These results support the central role afforded to autonomy in SDT and indicate that autonomy does not have to be actively undermined in order to forestall the internalization process.

Into another side of the interpersonal style are the controlling coaches may use extrinsic rewards and praise to induce engagement or persistence in certain behaviors and secure athlete compliance, as indicated the psychological literature. Controlling Coach Behaviors Scale (CCBS), a multidimensional self-report measure designed to assess sports coaches' controlling interpersonal style from the perspective of selfdetermination theory. It's very important which issues of motivation and psychological well-being (Bartholomew, Ntoumanis \& ThorgensenNtoumani, 2010). Despite, there is clearly evident that an interpersonal style of autonomy support is associated with positive results in cognitive, affective and behavioral outcomes (Mageau \& Vallerand, 2003), these authors indicated that teachers/instructors' training should be continuous so that learners have greater self-determined motivation, and over time their well-being will prevail through autonomous behavior.

Out of concern to assess this relationship in a health context, it was used the Motivational Aquatic Healthy Program (PAMS) in an aquatic environment class. This program proposes to use the relationship between the instructor-learner to create a positive atmosphere during the sessions which favors instructor behavior toward learners' autonomy and will likely positively influence basic psychological needs and self-determined motivation. The aim of this study was to determine, to what extent, instructor autonomy support, the psychological mediators and selfdetermined motivation predict psychological well-being and time spent in the daily activity of aquatic exercise. This is an intermediate step to reach for complete later the autonomy program to check the difference. In line with the studies reviewed, teacher autonomy support, the psychological mediators and self-determined motivation will positively predict psychological well-being and time spent doing activity per day.

\section{METHOD}

\section{Participants}

The sample consisted of 49 women aged between 21 and 73 years $(M=45.14 ; S D=1125)$ with an average experience of 2.61 years doing physical exercise in an aquatic environment, in a phase of reconciling work and family life. The sample was divided into an experimental group of 28 women $(\mathrm{M}=43.64 ; \mathrm{SD}=12.06)$, with an average experience of 3.05 years, and a control group of 21 women $(M=47.14 ; S D=0.01)$, with an average experience of 2.29 years. The sports council fixed two different enrollment schedules, which gave the participants total freedom to choose between them. The PAMS' instructor in the night schedule conducted the experimental group class. All participants gave their informed consent before starting the study in the aquatic context. Quantitative and qualitative data were collected and analyzed in parallel for complementing and going into detail about the variables' study (Gustafsson et al., 2015; Creswell, 2013; Östlund et al., 2011; Moran et al., 2011). Sparks (2015) thinks about only the experienced scholars or graduate students, will consider his critical reflections as worthy of attention this type of research.

\section{Measures}

Competition Autonomy support.

We used The Perceived Autonomy Support Scale for Exercise Settings (PASSES) by Hagger, Chatzisarantis, Hein, Pihu, Soós and Karsai (2007), validated in physical education classes in the Spanish context by Moreno, Parra, and 
González-Cutre (2008). It measures autonomy support that athletes perceive in their trainer. It consists of 12 items answered separately (e.g. "the monitor understands why I have decided to do physical exercise"). The preceding sentence is "In my directed physical exercise..." and the answers are given on a Likert-type scale ranging from 1 (strongly disagree) to 7 (strongly agree). The internal consistency in the pretest was .91, and in the posttest .91 .

\section{Psychological mediators}

We used the Basic Psychological Needs in Exercise Scale (BPNES) by Vlachopoulos and Michailidou (2006), validated in the healthy practitioners in the Spanish context by Sánchez, and Núñez (2007). The scale consists of 12 items related to competence (e.g., "I feel I have been making huge progress with respect to the end result I pursue in the physical exercise (PE) or sports program I do"), to autonomy (e.g., "The exercises I do in the PE or sports program I follow are highly compatible with my choices and interests"), and to relatedness (e.g. "I feel very comfortable when I do exercise with my peers"). The responses were measured on a Likert-type scale ranging from 1 (Totally disagree) to 6 (Very strongly agree), and the preceding sentence was "in my classes at the pool...". The internal consistency for competence in the pretest was .53 and in the posttest .68, for autonomy it was .68 for the pretest and .52 for the posttest, with respect to relatedness, the pretest was .78 and for posttest .71. However, in this study we contemplate the three dimensions in a single internal consistency, which was .76 in the pretest and .79 in the posttest, as done in previous studies (Bartholomew, Ntoumanis, Ryan, \& Thøgersen-Ntoumani, 2011).

\section{Motivation}

We used the Behavior Regulation in Exercise Questionnaire (BREQ-3) by Wilson et al (2006), validated in the healthy practitioners in the Spanish context by González-Cutre, Sicilia and Fernandez (2010). This scale measures athletes' motivation in doing physical exercise. It is composed of 23 items that relate to intrinsic regulation (e.g. "because I believe that exercise is fun!"), integrated regulation (e.g. "because it's in accordance with my life style"), identified regulation (e.g. "because I appreciate the benefits of physical exercise"), introjected regulation (e.g. "(because I feel embarrassed if I miss a session"), external regulation (e.g. "because others tell me that I must do it") and amotivation (e.g. "I don't see why do I need to do it"). The responses were assessed through a Likert-type scale ranging from 0 (Not true at all) to 4 (Totally true), preceded by the sentence "I do physical exercise in the water...". Internal consistency for the pretest was $.83, .84, .71, .56, .71$ and .74 , respectively, but in the posttest it was .71, .86, .71, .56, .70 and .11. Although internal consistencies for introjected regulation and amotivation were low, they can be accepted, as their dimensions consist of few items (Hair, Anderson, Tatham, \& Black, 1998). Selfdetermined motivation was assessed using a selfdetermination index (SDI) that has been shown to be valid and reliable in different studies (Chantal, Robin, Vernat, \& Bernache Asollant, 2005; Kowal \& Fortier, 2000) and is calculated with the following formula: (2x (IM knowledge + $\mathrm{IM}$ implementation + IM stimulation)/3) + $((\mathrm{EM}$ identified $+\mathrm{ME}$ integrated/2) $)-((\mathrm{ME}$ introject + ME external I)/2) - (2x amotivation) (Vallerand, 1997). By grouping these factors, we obtain a reliability index of .72 in both the pretest and the posttest.

\section{Psychological well-being}

We used the Psychological Well-being Scale (PWBS) by Ryff (1989), validated in the Spanish context by Diaz, Rodriguez-Carvajal, White, Moreno-Jiménez, Gallardo, Valle, and Van Dierendonck (2004). The reduced version of the scale is composed of 29 items, with six subscales: self-acceptance (e.g. "When I look at the story of my life, I am pleased with how things have turned out"), positive relationships (e.g. "I often feel lonely because I have few close friends with whom to share my concerns"), autonomy (e.g. "I am not afraid to voice my opinions, even when they are in opposition to the opinions of most people"), environmental mastery (e.g. "In general, I feel I am in charge of the situation in which I live"), personal growth (e.g. "I have the sense that I have developed a lot as a person over time ") and 
purpose in life (e.g. "I enjoy making plans for the future and working to make them a reality"). It is answered on a Likert-type scale with scores between 1 (Strongly disagree) and 6 (Fully agree). In this study we used a single measure of psychological well-being composed of all the dimensions. The total internal consistency of the scale in pretest was .82 , and in posttest .84 .

\section{Accelerometer}

To analyze physical activity during participants' daily activities, a record was made using an accelerometer which was worn on the right hip level with the iliac crest (Evenson et al., 2008; Treuth et al., 2004a), for a whole week before the intervention, and another week just after. The material used for recording data was an activity monitor Actigraph GT3X-Plus, which uses a solid triaxial accelerometer to measure the amount and frequency of activity in minutes. The program used for processing the data treatment was the ActiLife 6 software suite.

\section{Semi-structured interview}

For the qualitative assessment a semistructured interview was conducted with questions concerning motivation (e.g. "What reasons motivate you to do physical exercise and follow a healthy diet?"), teacher's style (e.g. "What do you prefer a monitor who gives you orders or one who guides you?"), competition (e.g. "Do you feel competent and capable of successfully completing the session?"), relationship (e.g. "Do you feel close to and relate to classmates?"), autonomy (e.g. "Do you feel that you can make decisions during workouts?"). An audio recording of the interview was made to make a subsequent analysis of the information collected.

\section{Instructor's training}

A physical exercise instructor was recruited for this study for the following reasons. (a) a coherent teaching style beyond the elements dealt with in the study and (b) to design a program to be implemented over a period of three months. Prior to the study, the instructor participated in an autonomy support workshop. In this workshop, participants are taught the concepts of motivation advocated in the SDT (Deci \& Ryan 2002) and instruction behaviors to facilitate higher levels of autonomy support, while controlling style statements are reduced during exercise sessions (Perlman, 2015; Perlman \& Webster, 2011; Reeve et al., 2004). During the workshop, they observe a teacher using autonomy support and in order to develop their own instruction behaviors they teach some lessons to university students. Once the instructor completed the workshop, measurements were carried out in a pilot study of four classes with students that had nothing to do with the present study. The purpose of the pilot study was to assist the instructor and ensure the correct implementation of each approach (autonomy support and control), and thereby, achieve an intra-observer reliability of at least $90 \%$.

\section{Procedures}

The Firstly, as the sample was not randomized, we used a quasi-experimental design: a pre-post design with two groups, one was quasi-control, which measured the dependent variable at the same time as the experimental group (Labrador, Fernández, \& Rincón, 2006). Selection was made after requesting the collaboration of the Council Sports Department who made the two aquatic facilities they have available to us and a sample of participants who do the different aquatic physical exercise activities. Finally, the aquafitness activity was selected, aquagym, because is realize in suspension on the water and this activity gather the most participants in the session. Two control groups were established for midday, and two experimental groups for the evening. All participants were asked to collaborate of their own free will and the research was approved from the research ethics board of the university authors prior to data collection (Register number: 2016.122E.OEP).

The initial phase of the intervention was the same for both groups and lasted for approximately one and a half hours. First, an initial interview was carried out, where they were asked about their experiences in doing sports, frequency, years of doing an activity, personal 
situation, among others. Following this, the semi-structured interview was recorded, and afterwards they were given a book of questionnaires to assess autonomy support (PASSES), the psychological basic needs (BPNES), self-determined motivation (BREQ-3) and psychological well-being (PWBS). On completing this initial evaluation, they were given an accelerometer (GT3-X plus), which they wore on the right hip for a week, and in the same week the intervention phase began (October 2013), which lasted 9 months until June 2014. Once the intervention phase was completed, the final assessment was made, which consisted of repeating the same procedure as already outlined above for the initial phase. To do so, it was carried out in the same place and at the same time. Both groups had two sessions a week, a total of approximately 48-50 sessions depending on bank holidays.

The control group, continued with the normal class dynamics, where there was no specific methodology, while the experimental group used a methodology based on autonomy support. Reliability of the intervention was assessed through the dimensions proposed by Sarrazin et al in 2006, which are based on distinguishing the instructor's different actions, statements and behaviors according to their being close to control, autonomy support or neutral style. Perlman (2015), considered as a class with support for autonomy should be $80 \%$ of the observed behaviors related to autonomy support. How our proposal was directed to conduct a joint interpersonal style, where predominate the autonomy support but with a percent of control style, we established as a criteria, that this mixed style is characterized by $60 \%$ of autonomy support behaviors and $40 \%$ control. Complete three dimensions were analyzed in each group during the whole process, at the beginning, middle and end of the program, in that order. The data obtained were: experimental group 25\%, $44.44 \%$ and $30.66 \%$ in autonomy support and control group $87.7 \%, 0 \%$ and $7.3 \%$ in control.

As previously mentioned, in the experimental group based on autonomy support, we used the PAMS. The aquatic instructor was trained to appropriately transmit a climate of autonomy support in the program during the sessions, which favors instructor behavior toward learners' autonomy, which will positively influence basic psychological needs and self-determined motivation. As indicated above, the aquatic instructor was trained to appropriately transmit a climate of autonomy support in the program. We opted for carrying out some semi-structured interviews with both groups to obtain greater wealth of the results. Once the interviews were transcribed, we carried out a conventional content analysis (Hsieh \& Shannon, 2005). The initial codification and categorization process was carried out by the lead researcher of this study, which was then monitored by experts and any discrepancies related to codification and categorization were discussed until a consensus was reached. This involved a transcoding and reclassification process until a categories and subcategories system was obtained which would be coherent for researchers and supported the results (see Table 2 and 3 ).

\section{Statistical analysis}

To analyze whether there were any differences between the control group and the experimental group in the study's target variables before the intervention, a Levene test was performed with the pretest variables of the groups. To answer the research questions, a repeated measures ANOVAs was performed (see Table 1). Attending to Cohen, 1988, the effect size was calculated using his cut-off values for small 0-0.2, medium 0.2-0.5 or large 0.5-0.8. Internal consistency of each factor was analyzed using Cronbach's alpha coefficient. The data were analyzed using the SPSS 21.0 statistics program.

\section{Preliminary analysis}

\section{RESULTS}

In the first place, in order to verify the homogeneity of the two groups before the intervention, an analysis of variance with a factor, considering as dependent variables all the initial steps in both groups (autonomy support, basic psychological needs, self-determined motivation, psychological well-being, and accelerometer). As a fixed factor (the group) differences (Wilks' Lambda $=.25, F(19,29)=4.66, p<.000, \eta 2=$ 
$.75)$ in the self-determined motivation $(F=7.18$, $p<.22, \eta 2=.03)$, being higher in the control group $(M=10.20 ; S D=1.26)$ than in the experimental group $(M=9.43, \mathrm{SD}=2.63)$. There were also differences in basic psychological needs $(F=0.18, p<.275, \eta 2=.025)$ being higher in the experimental group $(M=4.35, \mathrm{SD}=.36)$ than in the control group $(M=4.23, S D=.42)$. Finally, no differences were observed in the psychological well-being ( $F=0.31, \mathrm{p}<.084, \eta 2=.062)$ being higher in the control group $(M=4.16, S D=.34)$ than in the experimental group $(M=4.00, S D=$ $.30)$.

Table 1

Repeated Measures ANOVAs

\begin{tabular}{|c|c|c|c|c|c|c|c|}
\hline \multirow[t]{2}{*}{ Variables } & & \multicolumn{2}{|c|}{$\begin{array}{c}\text { Control } \\
(\mathrm{n}=21) \\
\end{array}$} & \multicolumn{4}{|c|}{$\begin{array}{l}\text { Experimental } \\
(\mathrm{n}=28)\end{array}$} \\
\hline & & $\mathrm{M}$ & SD & $\mathrm{p}$ & $\mathrm{M}$ & $\mathrm{SD}$ & $\mathrm{p}$ \\
\hline \multirow{2}{*}{ Autonomy support } & Pretest & 5.65 & 0.86 & \multirow{2}{*}{.09} & 5.76 & 0.61 & \multirow{2}{*}{$<.001^{* *}$} \\
\hline & Posttest & 5.88 & 0.72 & & 6.34 & 0.63 & \\
\hline \multirow{2}{*}{ Basic psychological needs } & Pretest & 4.23 & 0.42 & \multirow{2}{*}{$.00^{* *}$} & 4.35 & 0.36 & \multirow{2}{*}{$.00^{* *}$} \\
\hline & Posttest & 4.55 & 0.29 & & 4.57 & 0.33 & \\
\hline \multirow{2}{*}{ SDI } & Pretest & 10.20 & 1.26 & \multirow{2}{*}{.88} & 12.66 & 3.01 & \multirow{2}{*}{.58} \\
\hline & Posttest & 10.09 & 1.53 & & 12.99 & 2.66 & \\
\hline \multirow{2}{*}{ Psychological well-being } & Pretest & 4.16 & 0.34 & \multirow{2}{*}{.47} & 4.00 & 0.30 & \multirow{2}{*}{$<.001^{*}$} \\
\hline & Posttest & 4.16 & 0.30 & & 4.20 & 0.28 & \\
\hline \multirow{2}{*}{ Sedentary time (min) } & Pretest & 5633.81 & 493.56 & \multirow{2}{*}{$.00 * *$} & 5568.57 & 587.677 & \multirow{2}{*}{$.00^{* *}$} \\
\hline & Posttest & 5495.81 & 468.88 & & 5358.36 & 516.162 & \\
\hline
\end{tabular}

Note. ${ }^{*} \mathrm{p}<.05 ;{ }^{* *} \mathrm{p}<.001 ; \mathrm{M}=$ Mean; SD = Standard Deviation

\section{Qualitative analysis}

Autonomy support: "Well, the instructor has a lot ..., I don't know, it's great being with him, he talks to you, he motivates you. Also, he's like a friend, we only did gym before and now we feel more and more like companions" (E6). "What has changed most for me, and I've been coming to these sessions for several years, is everyone's participation and that the decision about activities is between the instructor and the pupils. Also the relationship between the students, which didn't exist before, and we didn't even know each other's name. Now, more or less, but we do have to have a partner or team, and we collaborate more and more and I think that's positive. What I mean is, it's become more than just coming and doing physical exercises, aerobics and you leave, now it's more participatory" (E2). “... it's not at all monotonous, the type of session, the games. I think I've mentioned it before to a classmate that

\section{Effects of intervention}

After the intervention, the experimental group $(n=28)$ showed significant increases in autonomy support $(\mathrm{p}<.001)$, basic psychological needs $\left(\mathrm{p}<.00^{* *}\right), \quad$ psychological well-being $(\mathrm{p}<.001)$ and the sedentary time $\left(\mathrm{p}<.00^{* *}\right)$. Finally, in the control group $(n=21)$, only the basic psychological needs and the sedentary time increased values after the intervention $(p<.001$, $)$ against the autonomy support and psychological well-being aren't significant (see Table 1). 
this program through the games you were doing in the water. It's been more as a team, especially Thursdays, which you always spent on games, you know what I mean. And that makes you relate more to other people, that's what I would most highlight in this" (E4) "No, I think as a result of the study, it's given us an opportunity and we relate to each other more openly. There's joking around and friendliness among everybody that've done it, of course it's also given us the chance, ha- ha, to get to know people, which is also very important. Not just coming, doing exercise and then leaving" (E28).

Psychological well-being: "A lot, a great deal, especially, I relax and when I know that it's pool day I feel really happy” (E13). “.. you see, I've managed to meet people, a great group, widen my circle of friends, physically I'm much better. They've made me smile, and it's also helped me psychologically" (E14).

Table 2

Categories and Subcategories System after the Data Analysis. Control Group (Posttest)

\begin{tabular}{|c|c|c|}
\hline Categories & Subcategories & Codes \\
\hline \multirow{3}{*}{$\begin{array}{l}\text { Instructor } \\
\text { /teacher }\end{array}$} & \multirow{3}{*}{ Education style } & Controller in the teaching-learning process. \\
\hline & & Autonomy support in the teaching-learning process. \\
\hline & & Both styles. \\
\hline \multirow{14}{*}{$\stackrel{\mathscr{0}}{\tilde{D}}$} & \multirow{2}{*}{$\begin{array}{c}\text { High self- } \\
\text { determinated } \\
\text { motivation }\end{array}$} & a. Maintaining a daily aquatic physical routine, although I should do more exercise. \\
\hline & & b. Improvement in aquatic skills and capabilities. \\
\hline & \multirow{3}{*}{$\begin{array}{l}\text { Low self- } \\
\text { determinated } \\
\text { motivation }\end{array}$} & a. Helps me to improve the symptoms and effects of my pathology or injury. \\
\hline & & b. Maintaining or losing weight. \\
\hline & & c. Improvement in my physical condition and my appearance. \\
\hline & \multirow{3}{*}{ Autonomy } & a. I can't make decisions during the sessions. \\
\hline & & b. I wasn't needed. \\
\hline & & c. I can make personal decisions but not group decisions. \\
\hline & \multirow{4}{*}{ Competence } & a. The session level has not reached my expectations. \\
\hline & & $\begin{array}{l}\text { b. I think that it has reached the level required in the program. I am always trying to give } \\
\text { my best. }\end{array}$ \\
\hline & & c. Not completed due to external problems. \\
\hline & & $\begin{array}{l}\text { d. I have improved throughout the program, although sometimes it has not been } \\
\text { possible. }\end{array}$ \\
\hline & \multirow{2}{*}{ Relatedness } & a. $\quad$ Relations with peers have improved as the program has developed. \\
\hline & & b. The same relation as at the start of the program. \\
\hline \multirow{11}{*}{ 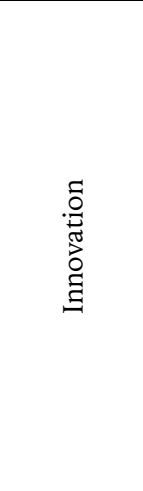 } & \multirow{3}{*}{ Facebook } & a. It seems an interesting and good idea because I love all its characteristics. \\
\hline & & $\begin{array}{l}\text { b. Thanks to the activity, I created Facebook although I haven't got round to logging in } \\
\text { very much. }\end{array}$ \\
\hline & & c. I don't have time for Facebook. I prefer face to face communication. \\
\hline & \multirow{8}{*}{ PAMS program } & a. $\quad$ Facebook. \\
\hline & & b. The sessions. \\
\hline & & c. Follow-up over time with tests. \\
\hline & & d. Aquatic activity/aquatic environment. \\
\hline & & Establish a daily aquatic physical exercise routine. \\
\hline & & f. The session atmosphere/ companionship. \\
\hline & & g. $\quad$ Relatedness with the instructor. \\
\hline & & h. The program in general. \\
\hline \multirow{4}{*}{ 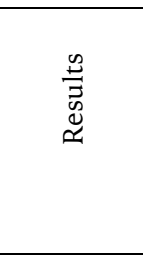 } & \multirow{2}{*}{$\begin{array}{l}\text { Psychological } \\
\text { well-being }\end{array}$} & $\begin{array}{l}\text { a. I feel good thanks to the aquatic physical exercise program and the development of } \\
\text { my capabilities. }\end{array}$ \\
\hline & & $\begin{array}{l}\text { b. I have achieved a feeling of well-being thanks to the personal growth that I have } \\
\text { experienced through the program. }\end{array}$ \\
\hline & \multirow{2}{*}{$\begin{array}{l}\text { Present } \\
\text { physical } \\
\text { activity }\end{array}$} & a. My physical condition is good after doing the aquatic physical exercise program. \\
\hline & & b. My physical condition is normal after the program. \\
\hline
\end{tabular}


Table 3

Categories and Subcategories System after the Data Analysis. Experimental Group (Posttest).

\begin{tabular}{|c|c|c|}
\hline Categories & Subcategories & Codes \\
\hline \multirow{3}{*}{$\begin{array}{l}\text { Instructor/ } \\
\text { teacher }\end{array}$} & \multirow{3}{*}{ Education style } & Controller in the teaching-learning process. \\
\hline & & Autonomy support in the teaching-learning process. \\
\hline & & Both styles. \\
\hline \multirow{14}{*}{$\begin{array}{l}\text { त्र } \\
\text { ర్ }\end{array}$} & \multirow{2}{*}{$\begin{array}{c}\text { High self- } \\
\text { determinated } \\
\text { motivation }\end{array}$} & a. Maintaining a daily aquatic physical routine, although I should do more exercise. \\
\hline & & Improvement in aquatic skills and capabilities. \\
\hline & \multirow{3}{*}{$\begin{array}{c}\text { Low self- } \\
\text { determinated } \\
\text { motivation }\end{array}$} & a. Helps me to improve the symptoms and effects of my pathology or injury. \\
\hline & & b. Maintaining or losing weight. \\
\hline & & c. Improvement in my physical condition and my appearance. \\
\hline & \multirow{4}{*}{ Autonomy } & a. I can't make decisions during the sessions. \\
\hline & & b. I wasn't needed. \\
\hline & & c. I can make personal decisions but not group decisions. \\
\hline & & d. I can make personal and group decisions in the session. \\
\hline & \multirow{3}{*}{ Competence } & $\begin{array}{l}\text { a. I think that it has reached the level required in the program. I am always trying to give } \\
\text { my best. }\end{array}$ \\
\hline & & b. Not completed due to external problems. \\
\hline & & c. I have improved throughout the program, although sometimes it has not been possible. \\
\hline & \multirow{2}{*}{ Relatedness } & a. Relations with peers have improved as the program has developed. \\
\hline & & b. The same relation as at the start of the program. \\
\hline \multirow{9}{*}{ 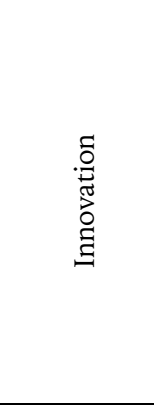 } & \multirow[b]{2}{*}{ Facebook } & a. It seems an interesting and good idea because I love all its characteristics. \\
\hline & & $\begin{array}{l}\text { b. Thanks to the activity, I created Facebook although I haven't got round to logging in } \\
\text { very much. }\end{array}$ \\
\hline & \multirow{7}{*}{ PAMS program } & a. $\quad$ Facebook. \\
\hline & & b. The sessions. \\
\hline & & c. Follow-up over time with tests. \\
\hline & & d. Aquatic activity/ aquatic environment. \\
\hline & & e. The session atmosphere/ companionship. \\
\hline & & f. Relatedness with the instructor. \\
\hline & & g. The program in general. \\
\hline \multirow{4}{*}{ 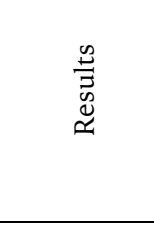 } & \multirow{2}{*}{$\begin{array}{l}\text { Psychological } \\
\text { well-being }\end{array}$} & $\begin{array}{l}\text { a. It feels good thanks to the aquatic physical exercise program and the development of } \\
\text { my capabilities. }\end{array}$ \\
\hline & & $\begin{array}{l}\text { b. I have achieved a feeling of well-being thanks to the personal growth that I have } \\
\text { experienced through the program. }\end{array}$ \\
\hline & \multirow{2}{*}{$\begin{array}{l}\text { Present physical } \\
\text { activity }\end{array}$} & a. My physical condition is good after doing the aquatic physical exercise program. \\
\hline & & b. My physical condition is normal after the program. \\
\hline
\end{tabular}

Sedentary time: "Well, because I do exercise, eat healthily, I'm active and I've got a happy life" (C12). "Much more agile, more flexible and I don't get so physically tired. Yes, now I've also got more strength in my arms and legs, which I didn't have before" (E16). "I feel great, due to all the exercise that we're doing. I've noticed it at work, because I don't get as tired as I used to" (E26).

Self-determined motivation: “... everything's linked, because I feel better, I'm not in pain and I feel I can do more things at home, at work, it changes your mood and I'm much better in all aspects. When the day is over, when I began, I told you I had to divide my day up, because I couldn't cope with a whole day of activity and now I manage a whole day with hardly any naps, which is something that, before it was finish work and have a nap. Now it's like that it gives me energy, of course, I've changed my nap for daily exercise and I feel so much better" (C20). "I think so, I've gradually improved. I don't know, I don't know in what, but I'm much better. Yes, day to day you do more exercise and you don't get so tired when you go somewhere, everything is less difficult (E24). "I feel at ease, I come here very happy and I've learned to float a bit, I didn't even know how to swim or float" (E13).

\section{DISCUSSION}

The current situation of the population requires strategies to be used which generate a habit of doing healthy physical activity and sports in adults to improve their physical and 
psychological well-being (Fox et al., 2007). This has become one of the major concerns in the scientific community, and is also linked to the aquatic environment, which is very appealing because of its characteristics, as most of the adult population in Spain does aquatic activities, particularly swimming (García Ferrando, 1998, 2001; Sociological Spanish Research Center, 2000). It is well known that women are the majority of the participants in aquatic fitness programs, $86 \%$, as indicated by Moreno and Marin de Oliveira, (2002a), and it was a reason why this study examine only adult woman and how a physical exercise program through motivational strategies can affect them. This investigation adds to the literature on autonomy support in the healthy context, but also on other variables such as the interpersonal style and women in the aquatic environment. The most important contribution is the continuous inclusion of novelties in every session, by creating an expectation in the practitioners before they come to the class. Furthermore, the combination of both quantitative and qualitative analysis in this area is also a novelty.

Studies carried out in the aquatic context show that the perception of instructor autonomy support is a positive predictor of perceived autonomy in participants (Zazo \& MorenoMurcia, 2015), as well as in other sporting contexts in other studies (Balaguer et al., 2008). Therefore, autonomy support perception generated by the instructor incite autonomous behaviors in beginners, oriented toward the activity, encouraging unity among peers and obtaining a state of psychological well-being as an individual, (Balaguer, Castillo, \& Duda, 2008; Deci \& Ryan 1985; 1991; 2000;). It even leads to their continuing to do physical exercise in their leisure time (Mageau \& Vallerand 2007), doing their daily tasks more actively, despite possible changes, unforeseen events or problems that may arise. The hypothesis formulated for this study was confirmed, given that the motivational strategies used in this pilot aquatic physical exercise program for adult women led to an improvement in autonomy support, the psychological mediators (especially relatedness), psychological well-being and actively time spent per day.

This line of research should be pursued in the future, since few studies and programs have been developed in the aquatic environment that guarantee these results, and which help to modify and establish long-lasting behavior patterns in the population (Molinero et al., 2011). Some results, for example, the passion variable, is not predicted in research because maybe sports people do not understand this concept. However, the major limitation in this study is that no comparison was made between a controlling interpersonal style and the autonomy support measure. In addition, the frustration variable from the basic psychological needs was not measured so it could not be compared with BPNES and, consequently, it could not be included in the analysis within the PAMS program. Moreover, there is no PASSES scale validated for healthy sports people in the Spanish context, so there is no reliability if the study is based on scale measures that do not have similar samples. The extensive sample during the program meant it was impossible to perform more data measures, with the added drawback that a high number of sports people had already done this type of program before (2.61 and 3.05, control and experimental, respectively) which meant that the results regarding motivation were not those expected and this led to limitations in the study. In addition, it was necessary to control certain aspects, such as the time of the day the groups intervention was carried out, since the council's plans could not be modified. For these reasons, future research should analyze these and other variables in a random study, making comparisons between the different adult groups who do this healthy aquatic activity in order to confirm and enrich this investigation.

\section{CONCLUSION}

In summary, the purpose of the current research was evaluated the PAMS program and suggest it as a guide for aquatic instructors to be able to transmit their knowledge in order to build their own aquatic programs. Furthermore, the activity can be assimilated by encouraging novelty, instructor autonomy support and 
relatedness in the sessions; fulfilling personal expectations and the goals proposed before starting the program. This program with these special strategies such as cooperative games in short groups, social networks to promote the relatedness outside the sessions, chooses her music... Could lead participants to include this aquatic activity in their routine, like that increase the time they dedicate to their well being, health and quality of life.

\section{Acknowledgments:}

Express my gratitude of the Alicante Sport Council for collaborating in the investigation.

\section{Conflict of interests:}

Nothing to declare.

\section{Funding:}

Nothing to declare.

\section{REFERENCES}

Baecke J., Burema J., \& Frijters J. (1982). A short questionnaire for the measurement of habitual physical activity in epidemiological studies. The American Journal of Clinical Nutrition, 36, 936-942. https://doi.org/10.1093/ajcn/36.5.936

Balaguer, I., Castillo, I., \& Duda, J. L. (2008). Apoyo a la autonomía, satisfacción de las necesidades, motivación y bienestar en deportistas de competición: un análisis de la teoría de la autodeterminación [Autonomy support, needs satisfaction, motivation and well-being in competitive athletes: a test of the selfdetermination theory]. Revista de Psicología del Deporte, 17(1), 123-139.

Bartholomew, K., Ntoumanis, N., \& ThogersenNtoumani, C. (2010). The Controlling Interpersonal Style in a Coaching Context: Development and Initial Validation of a Psychometric Scale. Journal of Sport \& Exercise Psychology, 32(2), 193-216. https://doi.org/10.1123/jsep.32.2.193

Bartholomew, K. J., Ntoumanis, N., Ryan, R. M., \& Thøgersen-Ntoumani, C. (2011). Psychological need thwarting in the sport context: assessing the darker side of athletic experience. Journal of Sport \& Exercise Psychology, 33, 75-102. https://doi.org/10.1123/jsep.33.1.75

Brotons-Gil, E., García-Vaquero, M. P., Peco-González, N., \& Vera-Garcia, F. J. (2013). Flexion-rotation trunk test to assess abdominal muscle endurance: reliability, learning effect, and sex differences. Journal of Strength and Conditioning Research, 27,
1602-1608.

https://doi.org/10.1519/JSC.0b013e31827124d9

Chantal, Y., Robin, P., Vernat, J. P., \& BernacheAsollant, I. (2005). Motivation, sportsperson ship, and athletic aggression: a meditational analysis. Psychology of Sport and Exercise, 6, 233249.

https://doi.org/10.1016/j.psychsport.2003.10.01

Chatzisarantis, N. L., \& Hagger, M. S. (2009). Effects of an intervention based on self-determination theory on self-reported leisure-time physical activity participation. Psychology and Health, 24, 29-48.

https://doi.org/10.1080/08870440701809533

Cheon, S. H., \& Reeve, J. (2015). A classroom-based intervention to help teachers decrease students' amotivation. Contemporary Educational Psychology, 40 ,

99-111. https://doi.org/10.1016/j.cedpsych.2014.06.004

Creswell, J.W. (2013). Research design: qualitative, quantitative, and mixed methods approaches. Sage publications, Thousand Oaks

Deci, E. L., y Ryan, R. M. (1985). Intrinsic motivation and self-determination in human behavior. New York, New York: Plenum Press. https://doi.org/10.1007/9781-4899-2271-7

Deci, E. L., \& Ryan, R. M. (1991). A motivational approach to self: integration in personality. Nebraska Symposium on Motivation: Perspectives on motivation, USA: University of Nebraska Press, Lincoln 38, 237-288.

Deci, E. L., \& Ryan, R. M. (2000). The "what" and "why" of goal pursuits: Human needs and the self-determination of behavior. Psychological Inquiry, $\quad 11$ 227-268. https://doi.org/10.1207/S15327965PLI1104 01

Deci, E. L., \& R. M. Ryan. 2002. Handbook of SelfDetermination Research. New York, New York: The University of Rochester Press.

Díaz, D., Rodríguez-Carvajal, R., Blanco, A., MorenoJiménez, B., Gallardo, I., Valle, C., \& Van Dierendonck, D. (2006). Adaptación española de las escalas de bienestar psicológico de Ryff [Spanish adaptation of the scales of Ryff's psychological well-being]. Psicothema, 18(3), 572577.

Edmund, J., Ntoumanis, N., \& Duda, J. L. (2008). Testing a self-determination theory based teaching style intervention in the exercise domain. European Journal of Social Psychology, 38, 375-388. https://doi.org/10.1002/ejsp.463

Fox, K. R., Stathi A., McKenna J., \& Davis M. G. (2007). Physical activity and mental wellbeing in older people participating in the Better Ageing Project. European Journal of Applied Physiology, 100, 591-602. https://doi.org/10.1007/s00421-007-0392-0

García Ferrando, M. (1998). Estructura social de la práctica deportiva. En M. García Ferrando, N. Puig y F. Lagardera (Eds.), Sociología del deporte (pp. 41-67). Madrid, Spain: Alianza Editorial. 
González-Cutre, D., Sicilia, A., \& Fernández, A. (2010). Hacia una mayor comprensión de la motivación en el ejercicio físico: Medición de la regulación integrada en el contexto español [Toward a deeper understanding of motivation towards exercise: Measurement of integrated regulation in the Spanish context]. Psicothema, 22, 841-847.

Gustafsson, M., Kullén Engström, A., Ohlsson, U., Sundler, A. J. (2015). Nurse teacher models in clinical education from the perspective of student nurses: A mixed method study. Nurse Education Today. 35 (12), 1289-1294 https://doi.org/10.1016/j.nedt.2015.03.008

Hagger, M. S., Chatzisarantis, N. D., Hein, V., Pihu, M., Soós, I., \& Karsai, I. (2007). The perceived autonomy support scale for exercise settings (PASSES): development, validity, and crosscultural invariance in young people. Psychology of Sport and Exercise, 8(5), 632-653. https://doi.org/10.1016/j.psychsport.2006.09.00 1

Hsieh, H. F., \& Shannon, S. E. (2005). Three approaches to qualitative content analysis. Qualitative Health Research, 15(9), 1277-1288. Doi: https://doi.org/10.1177/1049732305276687

Kowal, J., y Fortier, M. S. (2000). Testing relationships from the hierarchical model of intrinsic and extrinsic motivation using flow as a motivational consequence. Research Quarterly for Exercise and Sport, 71, 171-181. https://doi.org/10.1080/02701367.2000.106088 95

Labrador, F. J., Fernández-Velasco, R., \& Rincón, P. P. (2006). Eficacia de un programa de intervención individual y breve para el trastorno por estrés postraumático en mujeres víctimas de violencia doméstica. International Journal of Clinical and Health Psychology, 6, 527-547.

Lonsdale, C., Rosenkranz, R. R., Sanders, T., Peralta, L. R., Bennie, A., Jackson, B., et al. (2013). A cluster randomized controlled trial of strategies to increase adolescents' physical activity and motivation in physical education: results of the Motivating Active Learning in Physical Education (MALP) trial. Preventive Medicine, 57, 696-702. https://doi.org/10.1016/j.ypmed.2013.09.003

Mageau, G. A., \& Vallerand, R. J. (2003). The coachathlete relationship: A motivational model. Journal of Sport Sciences, 21, 883-904. https://doi.org/10.1080/0264041031000140374

Markland, D., \& Tobin, V. (2010). Need support and behavioral regulations for exercise among exercise referral scheme clients: The mediating role of psychological need satisfaction. Psychology of Sport and Exercise, 11(2), 91-99. https://doi.org/10.1016/j.psychsport.2009.07.00 1

Molinero-González, O., Salguero-del-Valle, A., \& Márquez, S. (2011). Autodeterminación y adherencia al ejercicio: estado de la cuestión.
RICYDE. Revista Internacional de Ciencias del Deporte, 7(25), 287-304.

https://doi.org/10.5232/ricyde2011.02504

Moran, A., James, M., \& Kirby, K. (2011). Whatever happened to the third paradigm? Exploring mixed methods research designs in sport and exercise psychology. Qualitative Research in Sport, Exercise and Health, 3, 362e369. https://doi.org/10.1080/2159676X.2011.60784 3

Moreno, J. A., Parra, N., \& González-Cutre, D. (2008). Influencia del apoyo a la autonomía, las metas sociales y la relación con los demás sobre la desmotivación en educación física [Influence of autonomy support, social goals and the relationship with others on motivation in physical Education]. Psicothema, 20(4), 636-641.

Östlund, U., Kidd, L., Wengström, Y., Rowa-Dewar, N. (2011). Combining qualitative and quantitative research within mixed method research designs: A methodological review. International Journal of Nursering Studies.48, 369-383.

https://doi.org/10.1016/10.1016/j.ijnurstu.2010 .10 .005

Perlman, D. J. (2015). Help motivate the amotivated by being a supportive teacher. Physical Education and Sport Pedagogy, 20(2), 204-214. https://doi.org/10.1080/17408989.2013.868876

Quested, E., Ntoumanis, N., Viladrich, C., Haug, E., Ommundsen, Y., Van Hoye, A., Merce, J., Hall, H. K., Zourbanos, N., \& Duda, J L. (2013). Intentions to drop-out of youth soccer: A test of the basic needs theory amount European youth from five countries. International Journal of Sport and Exercise Psychology, 11, 395-407. https://doi.org/10.1080/1612197X.2013.83043 1

Reeve, J., Jang, H., D. Carrell, D., Jeon, S., \& Barch, J. (2004). Enhancing students' engagement by increasing teachers' autonomy support. Motivation and Emotion, 28(2), 147-169. https://doi.org/10.1023/B:MOEM.0000032312. 95499.6f

Rocchi, M., Pelletier, L., \& Desmarais, P. (2017). The validity of the interpersonal behaviors questionnaire (IBQ) in sport. Measurement in Physical Education and Exercise Science, 14(1), 15-25. https://doi.org/10.1080/1091367X.2016.12424 88

Ryff, C. (1989a). Beyond Ponce de Leon and life satisfaction: New directions in quest of successful aging. International Journal of Behavioral Development, 12, 35-55. https://doi.org/10.1177/016502548901200102

Ryff, C. (1989b). Happiness is everything, or is it? Explorations on the meaning of psychological well-being. Journal of Personality and Social Psychology, 57, 1069-1081. https://doi.org/10.1037/0022-3514.57.6.1069

Sánchez, J. M., y Núñez, J. L. (2007). Análisis preliminar de las propiedades psicométricas de la versión española de la Escala de Necesidades 
Psicológicas Básicas en el Ejercicio Físico. Revista Iberoamericana de Psicología del Ejercicio y el Deporte, 2(2), 83-92.

Sarrazin, P., Tessier, D., Pelletier, L., Trouilloud, D., \& Chantal, C. (2006). The effects of teachers' expectations about students' motivation on teacher's autonomy-supportive and controlling behavior. International Journal of Sport and Exercise Psychology, 4, 283-301.

Sarrazin, P., Vallerand, R., Guillet, E., Pelletier, L., \& Cury, F. (2002). Motivation and dropout in female handballers: a 21-month prospective study. European Journal of Social Psychology, 32, 395-418. https://doi.org/10.1002/ejsp.98

Shenton, A. K. (2004). Strategies for ensuring trustworthiness in qualitative research projects. Education for Information, 22, 63-75. https://doi.org/10.3233/EFI-2004-22201

Sparkes, A. C. (2015). Developing mixed methods research in sport and exercise psychology: Critical reflections on five points of controversy. Psychology of Sport and Exercise, 16 (Part 3), 49-59. http://dx.doi.org/10.1016/j.psychsport.2014.08. 014

Treuth, M. S., Schmitz, K., Catellier, D. J., McMurray, R. G., McMurray, D. M., Almeida, M. J., ... \& Pate,
R. (2004). Defining accelerometer thresholds for activity intensities in adolescent girls. Medicine and Science in Sports and Exercise, 36, 1259-1266.

Vallerand, R. J. (1997). Toward a hierarchical model of intrinsic and extrinsic motivation. Advances in experimental social psychology. New York, New York: Academic Press, 271-360. https://doi.org/10.1016/S0065-2601(08)600192

Vlachopoulos, S. P., \& Michailidou, S. (2006). Development and initial validation of a measure of autonomy, competence, and relatedness: The Basic Psychological Needs in Exercise Scale. Measurement in Physical Education and Exercise Science, 10 179-201. https://doi.org/10.1207/s15327841mpee1003_4 Wilson, P. M., Rodgers, W. M., Loitz, C. C., y Scime, G. (2006). "It's who I am ...9 really!" The importance of integrated regulation in exercise contexts. Journal of Applied Biobehavioral Research, 11, 79-104.

Zazo, R., \& Moreno-Murcia, J. A. (2015). Modelo predictivo de la conducta y el bienestar en practicantes de ejercicio físico acuático [Behavior's predictive model and well-being in aquatic exercise practitioners]. Apuntes de psicología, 33 (1), 31-38.

All content of Journal Motricidade is licensed under Creative Commons, except when otherwise specified and in content retrieved from other bibliographic sources. 